\title{
Māori identity development outside of tribal environments
}

\section{Karyn Paringatai}

Karyn Paringatai (Te Whānau-a-Hunaara, a hapū of Ngāti Porou) is a Lecturer in Te Tumu, School of Māori, Pacific and Indigenous Studies, at the University of Otago.

\begin{abstract}
Ethnic identity is formulated through participation and adherence to a shared belief system, knowledge of ancestry, geographical location and associated historical information. The arrival of Europeans in New Zealand and the subsequent changes that ensued, disrupted Māori epistemological systems. Sustained, prolonged and regular contact with other ethnicities influenced the importance of Māori language and culture to Māori people. This article begins by looking at factors that influence identity development before looking specifically at ethnic identity. It will then discuss these factors in relation to the development of a Māori identity. By drawing on research conducted with first-generation urban Māori born in Southland it will conclude by looking at some of the effects of growing up away from tribal areas on the development of their Māori identity.
\end{abstract}

\section{Introduction}

When someone openly identifies as being of Māori descent, there is an expectation that they know how to operate within a Māori paradigm according to tikanga Māori (Māori cultural values) and have a degree of linguistic ability. This is not always the case. The person's upbringing, their physical location, the community they grew up in and their interaction with their tribal area may not have been conducive to the acquisition of such knowledge. This article will look at how ethnic identity is constructed and the effects on people when the mechanisms that ensure the development of a secure ethnic identity are absent.

\section{Identity}

Identity is a construct commonly used by individuals to describe who they view themselves to be, and how they fi with others in the social world. It is a dynamic, complex and $\mathrm{fl}$ concept that is constantly changing as a person experiences new things and encounters new people. Identity is not something that is automatically assigned to each individual. It begins in infancy, is reformulated during adolescence and modifi in adulthood. It is continually developed and as such, 'there is something active about identity that cannot be ignored: it isn't 'just there', it's not a 'thing', it must always be established' (Jenkins, 2004).

Although each person's identity is unique, there are some aspects of our self that we share with other people. A personal identity is not a construct that belongs solely to an individual but is a product of relationships with other people and within social groups (Lawler, 2008). 
Individuals are members of a number of groups for varying reasons and these may be based on gender, sexual preference, class, religion and ethnicity for example. Some of these exist simply as a reference group (gender) whilst others have a more functional purpose that people actively participate in (religion, ethnicity).

Social identity maintains '...that individuals attribute value to the group in which they are members and derive their self-esteem from their feelings of membership within that group' (Viladrich \& Loue, 2009). Research in this area has shown that people attribute value to belonging to a group which, in turn, leads to positive self-esteem (Roberts, et al., 1999). Problems occur when the group is a minority group and is attributed low-status and faces constant discrimination by outsiders. Ethnic groups are therefore amongst those most at risk of developing a negative social identity (Phinney, 1990). Members of an ethnic minority '...may internalize the negative views of the dominant society [about their ethnic group], thereby developing a negative identity and self-hatred' (Phinney, 1989). According to Tajfel (1978, as cited in Phinney, 1989) they can either choose to accept these negative views or reject them in the search for their identity.

Ethnic identity is infl

by social context and external factors and has been described as '... an enduring, fundamental aspect of the self that includes a sense of membership in an ethnic group and the attitudes and feelings associated with that membership' (Phinney, 1996). There are three main categories that can be said to contribute to one's ethnic identity. The fi is a shared belief system in terms of language, marriage rituals and supernatural force. The second is shared ancestry which includes kinship with others tied to a particular geographical location and associated historical accounts. The third is the labelling of groups within this ethnic group by recognising the self in relation to others (Viladrich \& Loue, 2009). Further to this, Phinney (1990) also concurs that ethnic identity development, and understanding who we are as individuals, is constructed socially through an awareness of how we relate to, are part of, and negotiate with other people, cultures and social institutions.

Social identity is about linking the individual with others in a social situation and locating that person's position within a particular social setting. The symbolic representations that a group exhibits then become important features in the production of identities and take on significant meanings themselves, for example, the Māori language and culture.

As individuals we have to take up identities actively, those identities are necessarily the product of the society in which we live and our relationship with others. Identity provides a link between individuals and the world in which they live. Identity combines how I see myself and how others see me. Identity involves the internal and the subjective, and the external. It is a socially recognised position, recognised by others not just by me. However, how I see myself and how others see me do not always fit (Woodward, 2000).

A consequence of an identity that is socially derived is that people may be assumed to be something that they are not. Instead, they are given an identity that is reflective of the characteristic of that person's social standing within the group/s of which they are a member. This is not always the case for those who are only a member of a group by birthright, but are not a full or active participant in that group. They are then assumed to know certain things and adhere to particular conventions that are attributed to being a member of that group, when in fact they may have little knowledge of these things. 
Problems in identity formation arise when socialisation is unsuccessful. For example, a person belonging to a particular ethnic group socialised in a community not of the same ethnic background may not have the same attachment to their ethnic group as their parents or grandparents have. They therefore may not act or behave in a way that is characteristic of their ethnic group and they may not have the cultural knowledge that people expect them to have. Physically, they may look like they should possess certain ethnic knowledge and attributes associated with that group and, there is an expectation from other people that they do. They may feel stigmatised by society and trapped into socially predetermined roles based on their ethnic group membership over which they have no say. As a result, they are not able to reconcile their ethnic identity with their personal identity and may feel resentment towards their ethnicity in the process.

One of the main infl on social identity is the home environment, primarily the family unit. In terms of ethnic development, the home is usually where the cultural values, behaviours and norms are transmitted to the children. According to Gay (1985), '...unquestionably, many young ethnic minority children are socialized in their homes and communities to be proud of their ethnic identity and heritage'. Whilst this may be true for some, for others the family environment, for whatever reason, is not always conducive to developing an inherent pride in one's ethnic self. People are then forced to look beyond this social unit to institutions external to the home, such as school, church and sports clubs, for example, as a means of being socialised to be proud of their ethnic group. This may be particularly problematic if the community in which the person was raised is not their ethnic community. It then becomes an individual choice to pursue avenues available to develop ethnic awareness and pride which is not always an easy task to undertake.

Successful ethnic identity is not automatic just because someone is a member of an ethnic group. For whatever reason, barriers to ethnic minority identity integration can happen at all levels of development and can be put in place by the individual themselves, their family or existing social structures. Ethnic communities also rely on active participation in community affairs for that person's claim to their ethnic identity and membership in that group to be validated by its members. This may not always be achievable given the geographical scattering of people from the original community to elsewhere in the country or the world along with the financial costs and physical and emotional barriers associated with maintaining that participation.

\section{Māori identity}

Māori identity has traditionally been centred on belonging to a wider collective of whānau (extended family), hapū (sub-tribe) and iwi (tribe) groupings (O'Regan, 2001). It was also about having a connection to the land in which one has turangawaewae (descent-based affiliation to an area), a practised ability in the Māori language and customs, and historical, ancestral and mythological tribal knowledge (see Ritchie, 1963; Metge, 1967). These social groups were, and in some way still are, responsible for the intergenerational transmission of tribal and sub-tribal knowledge that fostered one's Māori identity. This information and these cultural markers of Māori identity, amongst others, are still seen as core components of contemporary Māori identity (Durie, 1997). 
The Māori community has always accepted as a member of their community anyone who has a Māori ancestor (Durie, 1997), no matter how distant that ancestor may be, and who chooses to acknowledge that part of their ethnicity. An emphasis has always been placed on whakapapa, or genealogical descent from a Māori person, and in Māori social situations there were no distinctions made between full-blood Māori and those of mixed descent (Mead, 2003). However, as interracial marriages between Māori and Pākehā became more prolific, the cultural and linguistic differences started to become blurred. Māori society has reached a point where a non-Māori ancestor, grandparent or parent, infiltrates most whakapapa, but this non-Māori ancestry has varying degrees of influence on each person's ethnic identification and cultural upbringing. The mix of different ethnic and cultural backgrounds can often lead to a blending or a complete abandonment of certain cultural activities and the use of the language within families (Yancey \& Lewis, 2009).

\section{Māori migration to Southland}

The urbanisation of the Māori population after World War Two saw the rapid movement of a mainly rural people to a number of urban centres around the country. The social, economic and political push-pull factors involved in this migration flow have been described in a number of publications (see Pearson, 1990; Metge, 1964). This research is usually conducted within North Island locations, particularly Auckland, where the Māori population is considerably larger and the Māori population increase of urban centres more noticeable. Of little interest to those who researched this topic, but still duly noted, is the movement of North Island Māori to the South Island. As a result, there are only a few publications that mention the statistical changes that occurred in the Māori population of Southland and the social changes that ensued as a result. This research has been largely empirical and generalises about these people's experiences based on the trends that have emerged from research based on North Island communities.

The Māori population of Southland has historically been quite small; however, the North-South migration of Māori in the middle of the twentieth century caused a noticeable increase to occur. The places these people were emigrating from were subsistence, agriculturally-based communities, where, it appears, the majority of the population was of Māori descent. By contrast, Southland had almost the opposite social and cultural demographics: a population dominated by Pākehā, many of whom descended from early settler families. I was born and raised in Invercargill. My whole world view has been informed by this upbringing. I was not raised within a home environment or a community that actively fostered my Māori identity; the decision to pursue that part of my ethnic identity was purely my own. The conscious realisation of my Māori ethnicity, and the sudden feeling of belonging to something much greater than what I had grown up with, led to the development of an insatiable appetite for knowing who I am and discovering that which makes me Māori and Ngāti Porou. However, I also struggle with how to balance this with my Pākehā ethnicity without either having to be compromised. I am proud of being Ngāti Porou, but equally I am just as proud of being a Southlander. Being continually defined solely based on my Māori ethnicity because I looked Māori and had a Māori name used to frustrate me, but it also scared me because for a long time I did not know what being Māori meant. I would avoid conversations with people I thought would judge my authenticity as a Māori person because I was unable to answer their questions about my whakapapa (genealogy, ancestry), my whānau (extended family) or my Māori cultural knowledge in general. 
A number of Māori who moved to Southland chose to stay, become permanent residents and raise their children there. Their decision to settle permanently in Southland and live outside of their tribal area affected their children's Māori identity development. The participants interviewed for my research all have one Māori (tribally affiliated to North Island iwi) and one non-Māori parent (from either Otago or Southland) and as such have two distinctive ethnic backgrounds, both culturally and linguistically, that they must negotiate. They are therefore members of both the minority and dominant cultures. They described their upbringing as largely Pākehā; reflective of the Southland communities they each grew up in. They faced expectations placed upon them by others (both Māori and non-Māori) to conform to a national image of what a Māori person should be and how a Māori person should act.

People can't understand why I can't play a guitar ... People will ask me if I can speak Māori and I kind of say, 'Well can you speak Scottish?' It's a real thing that I've had to deal with. I feel I'm being insulted or attacked but to me I don't understand other people's ignorance around that and I guess the ignorance comes from the fact that they didn't have to live it ... But I always think there's an expectation on me to be either confi in Mãori or to kind of fail in some way because I'm Māori. I always strive to be better, to work harder, to lead this great life almost because I'm Māori and to thumb my nose at people who thought that I may fail.

I remember being in the classroom and always being pointed out by teachers like, 'Oh [she] will understand this because she's Māori.' Legends of Māui or the story of Paikea, 'Oh [she] will know about this because these are her ancestors.' And feeling under pressure and feeling like, not a stupid Māori, but someone who didn't totally identify. Like my whole world wasn't Māori because of Mum so then feeling stupid that I didn't know what the teachers expected me to know which when I look back now, what a pack of idiots putting that pressure on a kid. I was 10 years old.

If I didn't know [I was] Ngāti Porou and [I was] Māori and all that sort of stuff, and [I] didn't know te reo and [I wasn't] encouraged to understand that side then I'd feel probably one of two ways: I'd either feel really pissed off that people make that assumption just 'cause I have a brown face and I'd feel very shy that I don't know that side.

When they went against these national stereotypes of what a Māori should know or do then they 'weren't really Māori'. These situations also created feelings of inferiority and embarrassment that inhibited their ability to feel pride in their Māori ethnicity, which in turn affected their identity as a person of Māori descent. Throughout their early childhood the participants were unaware of ethnic differences between themselves and others. However, when they began socialising outside of their immediate family network during their adolescence they began being defined and stereotyped ethnically with mixed results on each of the participants' attitudes towards their Māori identity.

I remember having a talk with one of my European cousins about what I was and just being a bit confused and having to ask Mum who I was ... I mean there was never any kind of secrets to my identity but I just don't think they saw it as that important.

To be honest, growing up I was a wee bit embarrassed to be Māori just 'cos it was a negative connotation towards Māori and maybe 'cos like Māori was such a minority in Gore. I don't know. Sometimes I just [wished I] wasn't Māori. 
They all categorically stated that they were of Māori descent, and were proud to do so, but the salience of their Māori identity was more prominent for some than others. Comfort was found amongst peers whose socio-cultural background reflected their own. It was within these friendships that they reconciled being Māori with their reality of growing up in Southland.

I selected Māori as a subject and then made friends who were Māori and were happy to be Māori, although not coming from staunch Māori backgrounds. I feel that [those] friendships kind of moulded [me]. Just kind of having friends who were Māori ... having a group that you could [just] be and it was ok.

It is within the home and the community that an ethnic identity is said to be best developed and maintained. The transfer of Māori cultural knowledge from their parents was minimal. For the majority of the participants the amount and type of information about their Māori ethnic background relayed to them through their parents during their childhood was negligible. They were aware of their Māori ethnic identity but, for many, their parents did not think it was something that needed to be overtly developed within them.

Being one or two of the only Māori kids at school I think everyone was consciously aware so you couldn't forget that you were Māori. They [her parents] didn't try explicitly to make [me] aware that [I was] Māori. I think mostly I just knew, like I always knew I was Māori but I didn't really know what that meant. When you're little all you know is that you've got a different skin colour to most people.

Within the home there was no distinction made between the ethnicity of either parent and the cultural nuances of each and there was no conscious teaching of either parent's culture.

Interaction with whānau occurred for the majority of the participants in terms of regular contact with their extended Pākehā family that were living in Southland. Whilst they no doubt provided familial support, empathy and compassion characteristic of Māori whānau, they could not provide access to Māori cultural and linguistic knowledge. For the majority, regular return visits to their tribal area did not occur at all or were irregular at best. Those that have been to their tribal areas had mixed reactions:

I had a cousin who is my age and she was always kind to me but just different. I think we were a week apart, [in] age, we physically could be sisters and yet personality we couldn't be more different and we both tried. But she'd jump on a horse and wouldn't understand why I wasn't following her. We went to my family's marae which is over the back of my uncle's house and I remember sitting there thinking I am as much of a part of this as all these other people and yet I couldn't be more removed too at the same time...I remember thinking, 'God what are we doing here? I don't want to be here and I don't know anybody and they're speaking Māori and assuming I can'. I didn't enjoy it.

There's this feeling I always get when I'm going home and driving up the coast and as soon as I hit Jeru [Hiruharama] it's like, 'Oh my God I'm just so where I'm supposed to be.' I get really warm fuzzies and I just instantly feel comfortable and know that it's home and know that I'll settle there one day and it's the coolest feeling and I don't get it in Invercargill. I don't know if it's 'cause I was brought up there [Invercargill] and I'm just over the place but I don't get it there only in Jeru or when I see the maunga [mountain]. I'm driving up the coast and I see Hiku[rangi] and it's like, 'Oh yeah there's my maunga man'. It's just a really cool feeling. 
It was like I'd never left, like I'd always been there. [My aunties] gave me a great big hug and a great big kiss and then Dad took off and I ended up in the kitchen. So it was like just slipping back into place. It's like a place that was waiting there and then you just got put back into it so it was like I'd never been away.

Only three of the six participants had returned to their tribal area at various stages in their lives prior to the commencement of this research. This sense of 'home' was only felt by two participants. Because all of the participants do not tribally affiliate to the Southland area, they did not grow up with regular contact with social institutions, such as the marae (meeting place, complex of buildings), nor were they able to participate in tribal events that occurred there or within their tribal community to gain cultural competency.

\section{Conclusion}

One must be descended from a New Zealand Māori in order to claim a Māori ethnic identity. Implicit in this defi is the necessary requirement of whakapapa. By being a descendant of a Māori person, individuals are born with a whakapapa into a whānau, hapu and iwi collective within which they are nurtured and developed. Tribal knowledge is transmitted through the generations using the nuances of the language to emphasise certain traits applicable to the identity of that whānau, hapū or iwi. Through tribal membership individuals are able to lay claim to a geographical area of New Zealand. They are able to stand on their marae, know that this is their tūrangawaewae and that their identity is etched into the walls of their ancestral meeting house and imprinted in the surrounding geographical landmarks. These cultural indicators of Māori identity were an inherent part of every inhabitant of New Zealand prior to European arrival and they were attributes shared amongst all tribes.

It can no longer be assumed that this is how children continue to be raised. Research and experience has already proven this to be true. The continued importance of these indicators has been hindered as many children are no longer raised to recognise the value or importance of these things on their Māori cultural identity. The urbanisation of Māori had an unexpected result on the identity shift of those migrants and the identity development of their children. It is with this in mind that we must be careful not to make assumptions about the cultural competency or knowledge of people just because they choose to acknowledge their Māori ethnicity. Many are still to recognise the value of their Māori identity and reconcile it with their upbringing. Therefore their children and grandchildren are not being raised in this way either. This is the reality for a growing number of Māori born in urban centres. There are two challenges. The first is to find a way in which they can reflect critically on their own experiences and decide what is right for them. The second challenge is for the social work profession to not assume anything about anyone because of the ethnic label they choose, their name or their skin colour.

\section{Questions for reflection}

What does this mean for indigenous social work practice in Aotearoa?

What kind of criteria is used when deciding how to prioritise whakapapa?

When young people are raised in an ethnic community other than their own, what kind of skills and knowledge are needed for non-Māori to work with them competently? 


\section{References}

Durie, A. (1997). Te aka matua: Keeping a Māori identity. In P. Te Whāiti, M. McCarthy \& A. Durie (Eds.), Mai $i$ Rangiātea: Māori wellbeing and development. Auckland: Auckland University Press.

Jenkins, R. (2004). Social identity (2nd ed.). London: Routledge.

Lawler, S. (2008). Identity: Sociological perspectives. Cambridge: Polity Press.

Mead, H. M. (2003). Tikanga Māori: Living by Māori values. Wellington: Huia Publishers.

Metge, J. (1964). A new Māori migration: Rural and urban relations in northern New Zealand. London: The Athlone Press, University of London.

O’Regan, H. (2001). Ko Tahu Ko Au: Kāi Tahu tribal identity. Christchurch: Horomaka Publishing.

Pearson, D. (1990). A dream deferred: The origins of ethnic conflict in New Zealand. Wellington: Allen \& Unwin.

Phinney, J. S. (1989). Stages of ethnic identity development in minority group adolescents. The Journal of Early Adolescence, 9, 34-49.

Phinney, J. S. (1990). Ethnic identity in adolescents and adults: Review of research. Psychological Bulletin, 108(3), 499-514.

Phinney, J. S. (1996). When we talk about American ethnic groups what do we mean? American Psychologist, 51(9), 918-927.

Ritchie, J. (1963). The making of a Māori: A case study of a changing community. Wellington: A H \& A W Reed.

Roberts, R. E., Phinney, J. S., Masse, L. C., Chen, Y. R., Roberts, C. R., \& Romero, A. (1999). The structure of ethnic identity of young adolescents from diverse ethnocultural groups. The Journal of Early Adolescence, 19, $301-322$.

Viladrich, A., \& Loue, S. (2009). Minority identity development. In S. Loue (Ed.), Sexualities and identities of minority women (pp. 1-17). Cleveland: Case Western Reserve University.

Woodward, K. (Ed.). (2000). Questioning identity: Gender, class, nation. London: Routledge.

Yancey, G., \& Lewis, R. (2009). Interracial families: Current concepts and controversies. New York: Routledge. 